\title{
Epileptic spasms in PPP1CB-associated Noonan-like syndrome: a case report with clinical and therapeutic implications
}

\author{
Chien-Heng Lin ${ }^{1 \dagger}$, Wei-De Lin ${ }^{2 \dagger}$, I-Ching Chou ${ }^{3,4}$, Inn-Chi Lee ${ }^{5}$, Hueng-Chuen Fan ${ }^{6,7}$ and Syuan-Yu Hong ${ }^{3,8^{*}}$
}

\begin{abstract}
Background: Noonan syndrome-like disorder with loose anagen hair-2 (NSLH2) is an extremely rare disease caused by a heterozygous mutation in the PPP1CB gene on chromosome 2p23. The syndrome causes not only numerous dysmorphic features but also hypotonia, developmental delay, and even intellectual disability. We report the first case of NSLH2 in Asia and the 16th in the world. Moreover, the first case of PPP1CB-related infantile spasms. The clinical and therapeutic significance is outlined in this paper.

Case presentation: We found a male infant presented with severe intractable epileptic spasms. Although certain clinical features of somatic dysmorphism were noted, numerous laboratory and neuroimaging studies failed to identify the cause. To determine the underlying etiology, whole-exome sequencing was conducted. We identified a de novo heterozygous mutation, NM_206876.1: c.548A > C (p.Glu183Ala), in the PPP1CB gene. His seizures were almost refractory to conventional antiepileptic drugs but relative seizure control was eventually achieved with a ketogenic diet.

Conclusion: This result expands the clinical spectrum of NSLH2 and strengthens the association between the PPP1CB gene and epileptic seizures. Furthermore, we suggest that the ketogenic diet can offer seizure reduction in particular drug-resistant epilepsy syndromes. Additional studies are warranted to clarify the pathogenic mechanisms underlying this PPP1CB mutation in epileptic seizures.
\end{abstract}

Keywords: Epileptic spasms, PPP1CB, Noonan syndrome-like disorder with loose anagen hair-2, NSLH2, Ketogenic diet, KD

\section{Background}

PP1-beta (symbolized PPP1CB) is a catalytic subunit of protein phosphatase-1 (PP1). PP1 is one of the four major serine/threonine-specific protein phosphatases involved in the dephosphorylation of numerous proteins. These enzymes work in opposition to protein kinases, which are implicated in the regulation of cell growth, proliferation, survival, differentiation, and cytoskeletal changes, to control the level of phosphorylation [1].

\footnotetext{
* Correspondence: dazingdog@hotmail.com

${ }^{\dagger}$ Chien-Heng Lin and Wei-De Lin contributed equally to this work.

${ }^{3}$ Division of Pediatrics Neurology, China Medical University, Children's

Hospital, Taichung, Taiwan

${ }^{8}$ Department of Pediatrics, China Medical University Hospital, 2 Yuh-Der

Road, Taichung 404, Taiwan

Full list of author information is available at the end of the article
}

PPP1CB is expressed abundantly in the human brain and spine $[2,3]$.

In 2014, Hamdan et al. reported a patient with a de novo 1-bp insertion in the PPP1CB gene (c.909dupA: p.Tyr450Ilefs*92), which was predicted to cause a frameshift mutation and premature termination codon. The patient's clinical features included severe intellectual disability, short stature, relative macrocephaly, large mouth, malar hypoplasia, and mildly increased cerebral spinal fluid spaces [4]. Subsequently, Gripp et al. and Ma et al. have respectively studied four and eight unrelated patients with mutations in the PPP1CB gene. All these patients exhibited relative or absolute macrocephaly, prominent forehead, low-set and posteriorly rotated ears, and developmental delay, as well as slow-growing, sparse, or unruly hair $[3,5]$. The PPP1CB gene has been

(c) The Author(s). 2018 Open Access This article is distributed under the terms of the Creative Commons Attribution 4.0 International License (http://creativecommons.org/licenses/by/4.0/), which permits unrestricted use, distribution, and 
associated with Noonan syndrome-like disorder with loose anagen hair syndrome (NSLH2).

Herein, we report a male infant with a PPP1CB mutation who presented not only with typical clinical features of NSLH2 but also epileptic spasms that were almost refractory to conventional antiepileptic drugs (AEDs). Eventually, relative seizure control was achieved through administering a ketogenic diet (KD). To the best of our knowledge, this is the first case of NSLH2 in Asia and the first case of PPP1CB-related infantile spasms. The clinical and therapeutic significance is outlined in this paper.

\section{Case presentation}

The proband patient was the first child of nonconsanguineous healthy parents. His mother gave birth to him at the age of 35 years without any complication. The proband was born at 39 weeks of gestation. His birth weight was $3100 \mathrm{~g}$ (30th percentile), his height was $49 \mathrm{~cm}$ ( 32nd percentile), and his head circumference (HC) was $36.2 \mathrm{~cm}$ (90th percentile). The Apgar score was $8 / 10 / 10$ at birth. The patient did not exhibit any perinatal brain injury, hypoxia, ischemia, cranial trauma, or infection of the central nervous system. Family history of complications, such as epilepsy, febrile convulsion, intellectual disability, and psychotic disorders, was also negative.

A general physical examination at 4 months revealed macrocephaly (HC: $43.5 \mathrm{~cm}$, 90th percentile), prominent forehead, low-set and posteriorly rotated ears, and sparse and slow-growing hair.

His neurological and developmental examination at 4 months demonstrated poor head control, hypotonia, less eye-object pursuit, and a less pronounced smile, but cooed occasionally. A follow-up at 14 months revealed that the patient was unable to sit stably or crawl even under an intensive early intervention.

Paroxysmal epileptic spasms and occasional erratic myoclonic seizures in clustered episodes were first noticed at the age of 4 months, and their frequency gradually increased with age: at 9 months, the patient experienced more than 20 episodes per day, with each episode lasting 1-2 min. An initial interictal electroencephalogram (EEG) at 4 months revealed multifocal spikes and high-voltage wave discharges predominantly in the posterior region (Fig. 1a). At 9 months, the interictal EEG evolved into a pattern of chaotic, disorganized rhythms with superimposed multifocal spike discharges (Fig. 1b).

Numerous AEDs in different combinations were administered at various time points since the patient was 4 months old, namely phenobarbital $(5 \mathrm{mg} / \mathrm{kg} / \mathrm{day})$, clonazepam (titrated to $0.1 \mathrm{mg} / \mathrm{kg} /$ day), topiramate (titrated to $9 \mathrm{mg} / \mathrm{kg} /$ day) and vitamins (pyridoxine, pyridoxal phosphate, biotin, folic acid, and vitamin B12), levetiracetam (titrated to $50 \mathrm{mg} / \mathrm{kg} /$ day), valproic acid (titrated to $30-40 \mathrm{mg} / \mathrm{kg} /$ day), and vigabatrin (titrated to $150 \mathrm{mg} / \mathrm{kg} /$ day). However, none of these treatments were effective in treating his seizures at the age of 10 months, at which time he was placed on a KD.

The following laboratory tests were conducted: urinary organic acids and an acylcarnitine profile; urine toxicology screen; blood gases and electrolytes (calculate anion gap); carbohydrate-deficient transferrin and biotinidase activity; serum chemistry of liver function tests, lactate, pyruvate, ammonia, and amino acids; cerebrospinal fluid (lactate, protein and glucose levels, cell count and microscopic differentiation, gram stain and cultures, bacterial antigens, polymerase chain reaction for herpes simplex virus and varicella-zoster virus). The results were all negative. Brain magnetic resonance imaging did not reveal any marked structural abnormalities. In addition, cardiac sonography at 4 months showed an atrial septal defect and peripheral pulmonary stenosis. Therefore, whole-exome sequencing (WES) was conducted to determine the underlying etiology.

Genomic DNA for WES was extracted from blood from affected and unaffected parents. Exome capture

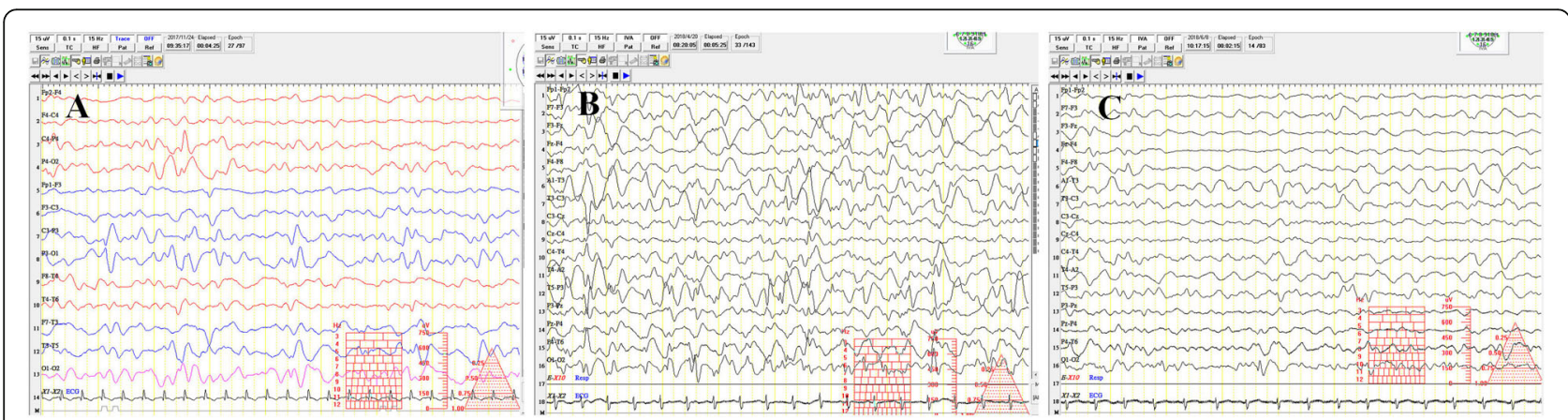

Fig. 1 The interictal electroencephalogram at the age of 4 months consists of multifocal spikes and high-voltage wave discharges appearing mainly in the posterior region (a). At 9 months, the interictal electroencephalogram showed a pattern of high-voltage, chaotic, random, and multifocal spikes with or without superimposed in slow waves, and spike and wave activities in almost all cortical areas (b). At 13 months, (after 3 months of the KD), his electroencephalogram showed only a few spikes in the posterior region (c) 
involved the use of the Agilent Human exome V5 $(51 \mathrm{Mb})$ capture kit. Sequencing was performed by $101 \mathrm{bp}$ paired-end sequencing on Hiseq2000 platform (Illumina, San Diego, USA) with an $\sim 150 \times$ depth of coverage. Raw reads were aligned to the Human genome (hg19/GRCh37) using the Burrows-Wheeler transform (BWA-MEM; v0.7.8). Variant calling was performed using the recommended best practices of GATK version 1.0.5506 (Broad Institute). Variant annotation and prioritization were performed using a well-developed pipeline, wANNOVAR [6, 7]. Candidate pathogenic variants were defined as missense, nonsense, splice-site and frameshift mutations with a minor allele frequency lower than 0.01, using the 1000 Genomes Project, dbSNP annotations, the Exome Aggregation Consortium (ExAC) and the Genome Aggregation Database (gnomAD). Several prediction programs: PolyPhen-2, Mutation Taster, CADD, and SIFT were used [8].

Only a single heterozygous missense mutation, namely NM_206876.1: c.548A > C (p.Glu183Ala), was identified in the PPP1CB gene. Variant description and mutation pathogenicity prediction were summarized in Table 1 . Sanger sequencing of a DNA sample confirmed that the variant in the patient did not exist in his parents (Fig. 2). Thus, the c.548A $>\mathrm{C}$ variant from the proband was confirmed to be de novo. The mutation was not identified in the 1000 Genomes Project, the gnomAD, or in ExAC or dbSNP databases. Additionally, the same variant was ever reported as pathogenic by Ma et al. in 2016 [3].

After administering numerous AEDs in different combinations without a favorable response, we introduced a KD since the patient was 10 months of age. The diet protocol suggested by Neal et al. [9]. was followed. We started by administering medium-chain triglycerides from an infant formula and carefully monitored his blood and urine glucose and ketones, liver and renal functions, triglyceride and cholesterol levels, electrolytes, growth, and body weight gain during the treatment period. Parents, nurses, child nutritionists, and caretakers were enrolled in this treatment plan and educated regarding suitable food items, in addition to the calculation and preparation of ketogenic meals. Subsequently, the spasms gradually decreased to less than 0-2 times per day, and no cluster form was noticed at the follow-up time of 14 months of age, although seizures were occasionally exacerbated during a febrile illness episode. An EEG at 13 months revealed few spikes, mainly in the posterior region (Fig. 1c). However, developmental delay with cognitive and gross motor impairment was still observed.

\section{Discussion and conclusion}

A de novo PPP1CB variant (c.548A > C:p.Glu183Ala) was detected through WES. To the best of our knowledge, this is the first reported case of NSLH2 in Taiwan and the 16 th in the world $[3,10,11]$. Compared with other rare diseases, a PPP1CB-related disorder is a relative new disease not generally known for its phenotype, genotype, or phenotype-gene relationship.

Since the first case of PPP1CB mutation was reported in $2014,{ }^{4}$ several missense mutations in $P P P 1 C B$ associated with NSLH2 have been identified by GeneDx and numerous studies, namely c.146C > G (p.Pro49Arg), c.166G > C (p.Ala56Pro), c.548A > C (p.Glu183Ala), c.548A > T (p.Glu 183Val), c.658C $>\mathrm{T}$ (p.Arg220Cys), c.754G $>\mathrm{T}$ (p.Asp 252Tyr), and c.820G > A (p.Glu274Lys) [3, 5, 10, 11].

On the basis of the clinical features of NSLH2 (Phenotype MIM No. 617506) summarized in Online Mendelian Inheritance in Man (OMIM) (https://www.omim.org), its characteristics include intellectual disability, relative or absolute macrocephaly; prominent forehead; low-set and posteriorly rotated ears; congenital heart disease including atrial septal defect, mitral and tricuspid valve insufficiency, hypoplastic left-sided aortic arch, coarctation of the aorta, dilated aortic root, and peripheral pulmonic stenosis; brain abnormalities including septo-optic dysplasia and mild ventriculomegaly; connective tissue abnormalities including high-arched palate, joint hypermobility, and translucent or doughy skin consistency; and epidermal features such as slow-growing, sparse, or unruly hair. Our patient's features exhibited a resemblance to other cases except that this patient experienced epileptic spasms; this was the first observed patient with a $P P P 1 C B$ mutation who had epileptic spasms.

The seizure mechanism and its response to the $\mathrm{KD}$ remain unknown. However, Noonan syndrome or Noonan-like syndrome, diseases typified by a disturbance of the transduction signal through the RAS/mitogen-activated protein kinase (MAPK) signal pathway are related to certain genes, such as PTPN11, SOS1, RAF1, KRAS, SHOC2, BRAF, NRAS, MAP2K1, RIT1, SOS2, LZTR1,

Table 1 Method of whole-exome sequencing and the PPP1CB mutation identified in the patient

\begin{tabular}{|c|c|c|c|c|c|c|c|c|}
\hline \multirow{2}{*}{$\begin{array}{l}\text { Patient } \\
\text { ID }\end{array}$} & \multirow[t]{2}{*}{ Variant with NM No. } & \multicolumn{2}{|l|}{$\mathrm{AF}$ in } & \multicolumn{5}{|c|}{ Mutation pathogenicity prediction } \\
\hline & & $1 \mathrm{KGP}$ & gnomAD & $\begin{array}{l}\text { Polyphen HDIV } \\
\text { score (pred) }\end{array}$ & SIFT_score (pred) & LRT score (pred) & $\begin{array}{l}\text { Mutation Taster } \\
\text { score (pred) }\end{array}$ & Reference \\
\hline LCY03 & $\begin{array}{l}\text { PPP1CB: NM_206876.1: } \\
\text { c.548A > C (p.Glu183Ala) }\end{array}$ & - & - & $0.014(B)$ & $0.01(\mathrm{D})$ & $0(D)$ & $0.81(\mathrm{D})$ & Ma et al. [3]. \\
\hline
\end{tabular}

Pred prediction, AF allele frequency, 1KGP 1000 Genomes Project; gnomAD The Genome Aggregation Database; -, not present, $B$, benign $D$ deleterious, SIFT sorting intolerant from tolerant, $L R T$ Likelihood Ratio Test 


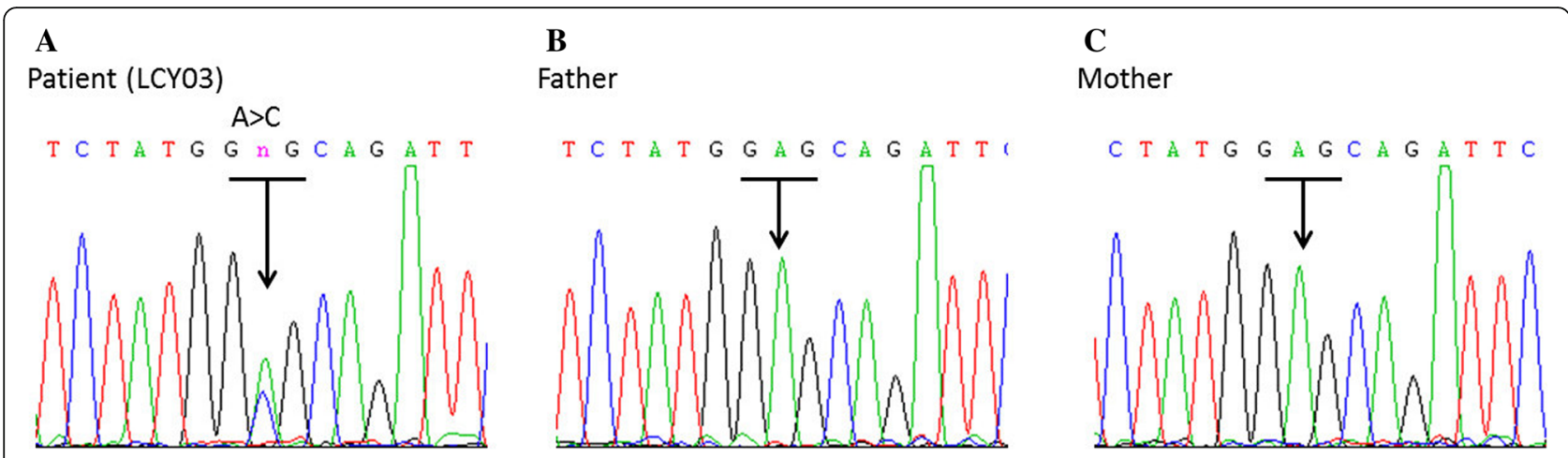

Fig. 2 Sequencing results of the de novo mutation in the PPPICB gene. The arrow indicates an A-to-C substitution at nucleotide 548 (c.548A >C, p.Glu183Ala) in the patient (a). This gene was normal in his father (b) and mother (c)

A2ML1 and PPP1CB [5, 12, 13]. Notably, although seizure disorder $(13 \%)$ is not uncommon in patients with Noonan syndrome [14], neurological impairment in patients with mutations in the RAS/MAPK pathway could be more severe and linked to certain forms of refractory epilepsy, especially epileptic encephalopathy and infantile spasms [15-17].

Strategies for treating RAS/MAPK-related seizures have not been established. In the aforementioned studies, Adachi et al. [17] reported two individual cases of cardiofaciocutaneous syndrome with severe neurological impairment and infantile spasms caused by heterozygous mutations in
KRAS and BRAF genes. None of the AEDs were effective in treating their seizures, but the patient with KRAS mutation (p. D153V) had a partial response to ACTH therapy. The clinical and genetic characteristics of RAS/ MAPK-associated epilepsy syndromes are summarized in Table 2 [15-18]. In recent studies, the ketogenic diet has proven to be a safe and effective treatment for children with not only drug-resistant epilepsies but also epileptic encephalopathies [19-23]. However, some adverse effects that can happen in the short-term when using dietary treatment of KD should be kept in mind and closely monitored, e.g. gastrointestinal symptoms; dyslipidemia;

Table 2 Clinical and genetic characteristics of RAS/MAPK-associated epileptic encephalopathies

\begin{tabular}{|c|c|c|c|c|}
\hline Clinical manifestation & RAS/MAPK-associated genes & & & \\
\hline & BRAF & MEK1 & KRAS & PPP1CB \\
\hline Associated syndrome & CFC & CFC3 & Noonan syndrome 3 & NSLH2 \\
\hline Reported mutations & $\begin{array}{l}\text { L485F; L485S; F468S; } \\
\text { Q257R; del E11; F595 L; } \\
\text { T599R; G534R; D638E; } \\
\text { K499 N }\end{array}$ & F53F; Y130N & D153V & E183A \\
\hline $\begin{array}{l}\text { Age of onset of epileptic } \\
\text { encephalopathies }\end{array}$ & Birth to $11 y$ & $\begin{array}{l}2 \text { reported patients } \\
\text { (1y and15y) }\end{array}$ & $3 \mathrm{~m}$ with $\mathrm{Myo} / 11 \mathrm{~m}$ with $\mathrm{IS}$ & $4 \mathrm{~m}$ \\
\hline Seizure type & $\begin{array}{l}\text { CPS, GTCS or sGTCS, Abs, IS, } \\
\text { Tonic spasms, SE }\end{array}$ & GTCS, Abs, CPS & IS, Myo & IS, Myo \\
\hline Interictal EEG & $\begin{array}{l}\text { Hypsarrhythmia (some } \\
\text { patients) }\end{array}$ & $\begin{array}{l}\text { Focal epileptiform } \\
\text { discharges to } \\
\text { hypsarrhythmia. }\end{array}$ & $\begin{array}{l}\text { Hypsarrhythmia }(11 \mathrm{~m}) \text {; } \\
\text { asynchronous slow waves with } \\
\text { irregular spike-wave or polyspikes } \\
\text { with and without waves }(6 \mathrm{y}) \text {. }\end{array}$ & $\begin{array}{l}\text { Chaotic, high voltage, polymorphic } \\
\text { delta and theta rhythms with } \\
\text { superimposed multifocal spikes } \\
\text { and wave discharges. }\end{array}$ \\
\hline Development delay & Severe & Severe & Severe & Moderate to severe \\
\hline $\begin{array}{l}\text { Seizures refractory to AEDs } \\
\text { or required multiple } \\
\text { AEDs use }\end{array}$ & Yes & Yes & Yes & Yes \\
\hline Seizure prognosis & Difficult to control & Difficult to control & Controlled with ACTH & Favorable to KD \\
\hline Brain MRI & $\begin{array}{l}\text { Cortical atrophy, } \\
\text { hypoplastic CC }\end{array}$ & $\begin{array}{l}\text { Hydrocephalus, } \\
\text { cortical atrophy }\end{array}$ & $\begin{array}{l}\text { Cortical atrophy, agenesis } \\
\text { of the CC }\end{array}$ & Unremarkable \\
\hline References & {$[15-18]$} & [15] & [18] & The present study \\
\hline
\end{tabular}

CFC Cardiofaciocutaneous syndrome, CFC3 Cardiofaciocutaneous syndrome 3, GTCS generalized tonic-clonic seizure, sGTCS secondarily generalized tonic-clonic seizure, CPS complex partial seizure, Abs absence seizure, Myo myoclonic seizure, status epilepticus, SE, IS infantile spasms, AEDs antiepileptic drugs, ACTH adrenocorticotropic hormone, $K D$ ketogenic diet, $M R I$ magnetic resonance image, $C C$ corpus callosum, m: months, $y$ years 
hypoglycemia; hyperuricemia; hypoproteinemia; hypomagnesemia; hyponatremia; hepatitis and metabolic acidosis; nephrolithiasis; osteopenia, osteoporosis and bone fractures; growth failure. Fortunately, our patient further proves the efficacy of the ketogenic diet for PPP1CBrelated Noonan syndrome presenting as infantile spasms and no obvious side effects were observed [24]. However, whether the KD would also have been effective in our patient for treating earlier seizure occurrences could not be investigated. Moreover, limited data for epileptic seizures associated with PPP1CB mutations are available in the worldwide population. However, more in-depth studies with additional patient data to explore the efficacy of the $\mathrm{KD}$ for treating epileptic seizures caused by PPP1CB mutations are essential. In conclusion, our study expands the clinical spectrum of NSLH2 and strengthens the association between the PPP1CB gene and epileptic spasms. Furthermore, we suggest that the KD be considered when seizures are medically refractory. Additional investigations are warranted to clarify the genotypephenotype correlations of several genes in the RAS/ MAPK signaling pathway and their associations with epileptic seizures or encephalopathies.

\section{Abbreviations \\ AEDs: antiepileptic drugs; EEG: electroencephalogram; HC: head circumference; KD: ketogenic diet; MAPK: mitogen-activated protein kinase; NSLH2: Noonan syndrome-like disorder with loose anagen hair-2; WES: whole-exome sequencing}

\section{Acknowledgments}

We would like to thank the Genetic Medicine Laboratory of China Medical University Hospital for giving support and assistance to this work. We also want to thank Ni-Chung (Nina) Lee because she stimulated our enthusiasm for neurogenetics and provided assistance for this work.

\section{Availability of data and materials}

All data related to this case report are contained within the manuscript.

\section{Authors' contributions}

SYH provided treatment to the patient, collected the data and wrote the draft. CHL and WDL participated in the design of the case report and wrote the manuscript. ICC provided her experience for the patient' s treatment, especially the use of ketogenic diet and modified the manuscript accordingly. ICL and HCF made the new Table 2 to meet the requirements of reviewers and participated in the editing and revising the manuscript and supervised this publication. All authors read and approved the final manuscript.

\section{Ethics approval and consent to participate}

Consent for discussion of the clinical history was provided by the family. The study protocol was approved by the Ethics Review Board of the China Medical University ethics committee (Approval \# CMUH105-REC3-123 and \#CMUH106-REC1-149 and \# CMUH107-REC2-017). Written informed consent of participation was obtained from the legal guardians. A copy of the written consent is available for review by the Editor of this journal.

\section{Consent for publication}

The patient's guardians have consented to submission of this case report to the journal, and we have obtained a written informed consent.

\section{Competing interests}

The authors declare that they have no competing interests.

\section{Publisher's Note}

Springer Nature remains neutral with regard to jurisdictional claims in published maps and institutional affiliations.

\section{Author details}

'Division of Pediatrics Pulmonology, China Medical University, Children's Hospital, Taichung, Taiwan. ${ }^{2}$ Department of Medical Research, China Medical University Hospital, Taichung, Taiwan. ${ }^{3}$ Division of Pediatrics Neurology, China Medical University, Children's Hospital, Taichung, Taiwan. ${ }^{4}$ Graduate Institute of Integrated Medicine, College of Chinese Medicine, China Medical University, Taichung, Taiwan. ${ }^{5}$ Department of Pediatrics, Chung Shan Medical University Hospital and Institute of Medicine, School of Medicine, Chung Shan Medical University, Taichung, Taiwan. 'Department of Pediatrics, Tungs' Taichung Metroharbor Hospital, Wuchi, 435 Taichung, Taiwan. ${ }^{7}$ Department of Nursing, Jen-Teh Junior College of Medicine, Nursing and Management, 356 Miaoli, Taiwan. ${ }^{8}$ Department of Pediatrics, China Medical University Hospital, 2 Yuh-Der Road, Taichung 404, Taiwan.

Received: 16 July 2018 Accepted: 14 September 2018

Published online: 20 September 2018

\section{References}

1. Barker HM, Brewis ND, Street AJ, Spurr NK, Cohen PT. Three genes for protein phosphatase 1 map to different human chromosomes: sequence, expression and gene localisation of protein serine/threonine phosphatase 1 beta (PPP1CB). Biochim Biophys Acta. 1994;1220:212-8.

2. Bordelon JR, Smith Y, Nairn AC, Colbran RJ, Greengard P, Muly EC. Differential localization of protein phosphatase-1alpha, beta and gamma1 isoforms in primate prefrontal cortex. Cereb Cortex. 2005;15(12):1928-37.

3. Ma L, Bayram Y, McLaughlin HM, Cho MT, Krokosky A, Turner CE, et al. De novo missense variants in PPP1CB are associated with intellectual disability and congenital heart disease. Hum Genet. 2016;135:1399-409.

4. Hamdan FF, Srour M, Capo-Chichi JM, Daoud H, Nassif C, Patry L, et al. De novo mutations in moderate or severe intellectual disability. PLoS Genet. 2014;10:e1004772.

5. Gripp KW, Aldinger KA, Bennett JT, Baker L, Tusi J, Powell-Hamilton N, et al. A novel rasopathy caused by recurrent de novo missense mutations in PPP1CB closely resembles Noonan syndrome with loose anagen hair. Am J Med Genet A. 2016;170:2237-47.

6. Chang $X$, Wang K. WANNOVAR: annotating genetic variants for personal genomes via the web. J Med Genet. 2012;49:433-6.

7. Yang $\mathrm{H}$, Wang K. Genomic variant annotation and prioritization with ANNOVAR and wANNOVAR. Nat Protoc. 2015;10:1556-66.

8. Adzhubei IA, Schmidt S, Peshkin L, Ramensky VE, Gerasimova A, Bork P, et al. A method and server for predicting damaging missense mutations. Nat Methods. 2010;7:248-9.

9. Neal EG, Chaffe H, Schwartz RH, Lawson MS, Edwards N, Fitzsimmons G, et al. The ketogenic diet for the treatment of childhood epilepsy: a randomised controlled trial. Lancet Neurol. 2008;7:500-6.

10. Bertola D, Yamamoto G, Buscarilli M, Jorge A, Passos-Bueno MR, Kim C. The recurrent PPP1CB mutation p.Pro49Arg in an additional Noonan-like syndrome individual: broadening the clinical phenotype. Am J Med Genet A. 2017;173:824-8.

11. Zambrano RM, Marble M, Chalew SA, Lilje C, Vargas A, Lacassie Y. Further evidence that variants in PPP1CB cause a rasopathy similar to Noonan syndrome with loose anagen hair. Am J Med Genet A. 2017;173:565-7.

12. Garg S, Brooks A, Burns A, Burkitt-Wright E, Kerr B, Huson S, et al. Autism spectrum disorder and other neurobehavioural comorbidities in rare disorders of the Ras/MAPK pathway. Dev Med Child Neurol. 2017;59:544-9.

13. Kruszka P, Porras AR, Addissie YA, Moresco A, Medrano S, Mok GTK, et al. Noonan syndrome in diverse populations. Am J Med Genet A. 2017:173:2323-34

14. Romano AA, Allanson JE, Dahlgren J, Gelb BD, Hall B, Pierpont ME, et al. Noonan syndrome: clinical features, diagnosis, and management guidelines. Pediatrics. 2010;126:746-59.

15. Yoon G, Rosenberg J, Blaser S, Rauen KA. Neurological complications of cardio-facio-cutaneous syndrome. Dev Med Child Neurol. 2007:49:894-9.

16. Wakusawa K, Kobayashi S, Abe Y, Tanaka S, Endo W, Inui T, et al. A girl with cardio-facio-cutaneous syndrome complicated with status epilepticus and acute encephalopathy. Brain Dev. 2014;36:61-3. 
17. Adachi M, Abe Y, Aoki Y, Matsubara Y. Epilepsy in RAS/MAPK syndrome: two cases of cardio-facio-cutaneous syndrome with epileptic encephalopathy and a literature review. Seizure. 2012;21:55-60.

18. Aizaki K, Sugai K, Saito Y, Nakagawa E, Sasaki M, Aoki Y, et al. Cardio-faciocutaneous syndrome with infantile spasms and delayed myelination. Brain Dev. 2011;33:166-9.

19. Arya R, Peariso K, Gaínza-Lein M, Harvey J, Bergin A, Brenton JN, et al. Efficacy and safety of ketogenic diet for treatment of pediatric convulsive refractory status epilepticus. Epilepsy Res. 2018;144:1-6.

20. Li T, Cheng M, Wang J, Hong S, Li M, Liao S, et al. De novo mutations of STXBP1 in Chinese children with early onset epileptic encephalopathy. Genes Brain Behav. 2018:e12492. https://doi.org/10.1111/gbb.12492.

21. Su DJ, Lu JF, Lin LJ, Liang JS, Hung KL. SCN2A mutation in an infant presenting with migrating focal seizures and infantile spasm responsive to a ketogenic diet. Brain Dev. 2018:40:724-7.

22. Wirrell E, Eckert S, Wong-Kisiel L, Payne E, Nickels K. Ketogenic diet therapy in infants: efficacy and tolerability. Pediatr Neurol. 2018:82:13-8.

23. Martin HC, Kim GE, Pagnamenta AT, Murakami Y, Carvill GL, Meyer E, et al. Clinical whole-genome sequencing in severe early-onset epilepsy reveals new genes and improves molecular diagnosis. Hum Mol Genet. 2014;23:3200-11.

24. Kang HC, Chung DE, Kim DW, Kim HD. Early- and late-onset complications of the ketogenic diet for intractable epilepsy. Epilepsia. 2004;45:1116-23.

Ready to submit your research? Choose BMC and benefit from:

- fast, convenient online submission

- thorough peer review by experienced researchers in your field

- rapid publication on acceptance

- support for research data, including large and complex data types

- gold Open Access which fosters wider collaboration and increased citations

- maximum visibility for your research: over $100 \mathrm{M}$ website views per year

At $\mathrm{BMC}$, research is always in progress.

Learn more biomedcentral.com/submissions 